\title{
Effect of Monetary Policy on Investment in Russian Regions
}

\author{
Andrei Shevelev, Bank of Russia \\ andrew.shevelev@gmail.com \\ Maria Kvaktun, Bank of Russia \\ marya-kvaktun@yandex.ru \\ Kristina Virovets, Bank of Russia
}

kristi.prof@mail.ru

This paper assesses the effect of monetary policy on investment in Russian regions. In the first stage of the research, we estimate the responses of regional investment to interbank market rate shocks using structural vector autoregressions. In the second stage, we estimate regression models using impulse responses as dependent variables and explanatory factors as independent variables. The regression calculations are performed using the Elastic Net regularisation technique. We find that regions with higher shares of manufacturing, agriculture, and construction are more responsive to monetary policy shocks. In addition, we identified the high importance of these sectors in explaining the different effects of monetary policy on investment. The results also show that the larger is the share of the mining and quarrying sector in the gross regional product (GRP) and the greater the imports to GRP ratio, the smaller is the absolute change in investment from a monetary policy shock.

Keywords: monetary policy, investment, interbank market rate, transmission mechanism, structural vector autoregression, impulse response functions, Elastic Net, panel vector autoregression

JEL Codes: C3, E43, E52, E22
Citation: Shevelev, A., Kvaktun, M. and Virovets, K. (2021). Effect of Monetary Policy on Investment in Russian Regions. Russian Journal of Money and Finance, 80(4), pp. 31-49.

doi: 10.31477/rjmf.202104.31

\section{Introduction}

Since 2015, the Bank of Russia has conducted its monetary policy within the framework of an inflation targeting regime. The main Bank of Russia instrument in achieving the inflation target is the key rate, which affects the change in money

\footnotetext{
1 The views expressed in this paper are solely those of the authors and do not necessarily reflect the official position of the Bank of Russia. The Bank of Russia shall not be responsible for the content of this report.
} 
market rates, which in turn is translated into the interest rates on loans and deposits. Based on these changes, households and firms make their own decisions about consumption, saving, and investment (Figure 1).

Figure 1. Standard New Keynesian logic of the interest rate channel of the monetary transmission mechanism

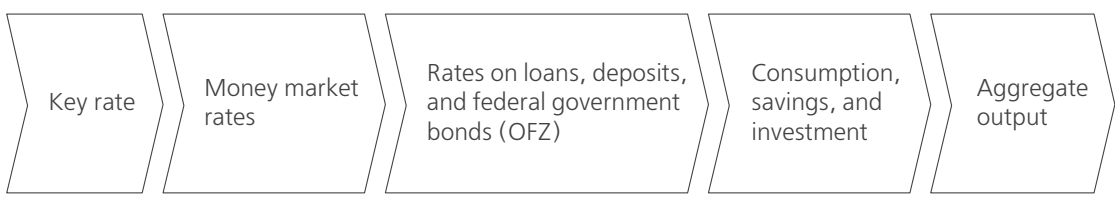

Source: compiled by the authors based on Mogilat (2017)

Thus, a change in the key monetary policy rate affects aggregate demand and its components, and through them, price dynamics. Therefore, the Bank of Russia analyses the state of the entire economy when making decisions on the key rate.

Due to the structural and economic differences between Russian regions, the effects of monetary policy on their economic activity can differ significantly. Investment is one of the key factors necessary for sustainable economic growth. Literature pays special attention to the importance of investment in the development of regions and in economic growth: Young (1993), Schmidt-Hebbel et al. (1994), Aganbegyan (2011; 2012), Bulatov (2011), Shcherbakov (2015), and others. Thus, the analysis of the regional heterogeneity of the effects of monetary policy on investment in Russian regions is relevant.

The objective of this paper is to estimate the effect of monetary policy on investment in Russian regions and to identify the reasons for the regional heterogeneity of effects.

The novelty of this research lies in its consideration of investment in Russian regions as a key indicator. Analysis of the existing literature has not revealed similar publications among Russian papers. In addition, previous research on the regional effects of monetary policy identifies factors in the heterogeneous effects of monetary policy by constructing multiple regressions or by determining correlations between variables. In our paper, we use regularised regression (Elastic Net, a machine learning method), which allows us to consider a large set of explanatory variables and highlight the most important among them.

The empirical basis of the research is statistical data that show the economic situation in 78 Russian regions from 2010 to 2019 on a quarterly basis.

The paper is structured as follows. Section 2 provides a review of literature on the regional effects of monetary policy. Section 3 is devoted to describing the methodology. Section 4 describes the data that were used in the models. Section 5 is devoted to the research findings. Section 6 summarises the main conclusions of the paper. 


\section{Literature review}

Since the early 1990s, researchers have begun to pay attention to the differing effects of monetary policy on different regions, as evidenced by the increase in the number of publications in this area. In most papers on this topic, the responses of indicators of regional economic activity to monetary policy shocks have been estimated using vector autoregression (VAR) models.

Ramaswamy and Sloek (1997) build VAR models for the EU countries based on data for 1972-1995, using the price level, output level, and short-term interest rate as variables in the models. The authors analyse the resulting impulse response functions (IRFs) and find that the EU countries can be divided into two groups. In the first group, a tightening monetary policy shock continues to affect regional output for almost twice as long as in the second group, while the cumulative decline in production in this group is almost twice as deep compared to the second group.

Later, researchers began to identify the factors of the heterogeneous effects of monetary policy on regional economic activity. The first work on this topic is Carlino and DeFina (1998), which builds structural VAR (SVAR) models for the US regions using data for 1958-1992. The models include the relative price of energy, the growth rate of money income, and various monetary factors. As for IRFs, the authors show that most regions have responses to monetary policy shocks close to the national average. These findings are robust to alternative indicators of monetary policy stance (Boschen and Mills (1995) measure, federal funds rate, etc.), model specification (in growth rates or levels), and economic activity (employment and others). The authors show which factors explain the heterogeneous effects of monetary policy on the economic activity of the individual states: it turns out that the regional response is greater in states with larger share of manufacturing in their GRP (the interest rate channel of the transmission mechanism) and higher share of small firms (the broad credit channel).

Subsequently, the methodology of Carlino and DeFina (1998) began to be actively applied to other countries. Arnold and Vrugt (2002) estimate the effect of monetary policy on regional production in the Netherlands. Using data for 1973-1993, they build a VAR model that includes the consumer price index, growth in aggregate real output by region and economic sector, and the short-term interest rate. They find that an increase in the interest rate has an adverse effect on output both in the regions and in the economic sectors. The most sensitive to the monetary policy shocks are trade, financial sector, industry, agriculture, and construction. The authors' findings are similar to those obtained by other researchers in the US and Great Britain.

Hayo and Uhlenbrock (2000) analyse the reasons for the asymmetric effects of monetary policy in Germany. In addition to the sectoral structure, the authors examine the effect of the exchange rate channel of the transmission mechanism. They show that regions with more export-oriented economic sectors are more 
susceptible to monetary policy shocks, that is, they react with a larger decline in production than regions with economic sectors less dependent on exports.

Svensson (2012) investigates the effect of monetary policy on employment in 21 regions of Sweden for 1993-2007 using SVAR model with exogenous external variables. He concludes that an increase in the interest rate leads to a significant decrease in regional employment in most regions of Sweden. However, some regions show an increase in employment in response to the same monetary policy shock. The author associates the significant differences between regions with the interest rate, the bank lending, and the exchange rate channels. He shows that a monetary policy shock adversely affects the economic activity of regions with a greater share of employment in the goods sector, with a smaller share of employment in the service sector, with a higher export intensity, and with a higher share of small firms.

Fraser et al. (2014) build a VAR model for Australian regions for 1985-2008 to show the different effects of monetary policy shocks on regional economic activity. The authors use the logarithms of real national GDP, real GRP, consumption index, real commodity price index, and trade weighted exchange rate index as the model variables. The model also includes inflation and interest rate on 30-day bank acceptance bills. The authors compare the effect of a monetary policy shock on the GDP and on the GRP in each region by comparing the GRP impulse responses with the confidence intervals for the national GDP impulse response. The paper concludes that Western Australia and Queensland differ from the other regions in their response to monetary policy, that is, their responses do not fit within the confidence intervals for national GDP impulse response. The authors explain this by the fact that these regions are not sufficiently diversified and that they are strongly dependent on mining and quarrying, but they do not substantiate this assumption with econometric tools. Authors propose the introduction of federal transfers for such regions in order to compensate for the effects of monetary policy on them.

Ridhwan et al. (2014) use VAR models to measure the effect of monetary policy shocks on the regional output in 26 provinces of Indonesia. The authors use quarterly data for 1990-2007 and conclude that there are significant interregional differences in response. In particular, the varying regional effects are associated with the sectoral structure, especially with the share of the manufacturing industry, which indicates the importance of the interest rate channel of the transmission mechanism. Provinces heavily dependent on the agricultural sector are less susceptible to monetary policy shocks, while provinces with larger share of production are more sensitive to changes in monetary policy. The paper also shows that the size of firms and banks, that is, the credit channel of the transmission mechanism, plays an important role in explaining regional differences. In general, both channels operate simultaneously within the framework of Indonesia's decentralised monetary policy and affect the real economy of the provinces. At the same time, the exchange rate channel turns out to be insignificant in explaining regional differences. The authors also emphasise that the effect of monetary policy 
shocks (in terms of output losses) tends to be much greater in developing countries than in developed ones.

Anagnostou and Papadamou (2015) apply the approach of Carlino and DeFina (1998) to explain the heterogeneous effects of monetary policy on the regions of Greece. The authors build a VAR model for each region using the following indicators: total employment, real GDP, short-term interest rate, and regional variables (GRP, household expenditure, investment, and employment). Based on the impulse responses obtained, they conclude that monetary policy has different effects on the regions of Greece. They also calculate the correlation between the shares of economic sectors in GRP and the two-year and seven-year impulse responses. As a result, they conclude that higher share of construction, agriculture, financial services, hotels, and trade in GRP leads to the region being more sensitive to the changes in interest rates; and if the mining and quarrying sector has a high share, this sensitivity decreases.

Basically, the papers above estimate the effect of monetary policy on regional output, but do not pay sufficient attention to the effect on regional investment, although the instruments of monetary policy through the transmission mechanism affect investment costs, which, in turn, affect investment and aggregate output.

In this paper, we examine the effect of monetary policy on investment and focus on the following transmission channels through which interest rates affect regional economies.

Firstly, the interest rate channel of the transmission mechanism plays an important role in explaining regional differences. Because regions have diverse sectoral structure, and sectors, in turn, depend in different ways on changes in interest rates, monetary policy shocks may have differing effects on regional investment. Regions are more vulnerable to monetary policy tightening if they have higher proportion of interest rate-sensitive economic sectors. For example, many of the papers cited above note manufacturing and construction are more dependent on lending compared to services, and therefore are more sensitive to monetary policy shocks. Therefore, relatively industrialised regions are more vulnerable to monetary policy tightening. Thus, the first reason for regional differences is the sectoral structure.

Secondly, regional differences can be explained through the credit channel. Regions with differing shares of small firms may respond differently to monetary policy (the broad credit channel). This happens because small firms are more dependent on bank loans compared to large ones, which have other sources of funding more readily available. Therefore, in regions with a high share of small firms, the adverse effect of monetary policy tightening on investment is likely to be higher. As a proxy for the credit channel, we use the indicator of the share of loans to smalland medium-sized enterprises (SMEs) in the total volume of loans to legal entities.

Thirdly, some authors demonstrate the importance of the exchange rate channel of the transmission mechanism, which affects aggregate demand through changes in the exchange rate. As a proxy for the exchange rate channel importance, we use the ratio of a region's imports to its GRP. 
In addition to the variables listed characterising the interest rate, credit, and exchange rate channels of the transmission mechanism, we use several more indicators, described in Section 5.4, to explain the factors of regional heterogeneity.

\section{Methodology}

In the first stage, we build SVARs for each region and obtain impulse responses of investment in Russian regions to an interbank market rate shock.

The VAR model is widely used to analyse the dynamics of interdependent macroeconomic variables. First introduced by Sims (1980), it has been widely adopted and further developed by Sims (1992), Bernanke and Blinder (1992), and other authors.

VAR can be represented as follows (1):

$$
Y_{t}=c+B_{1} Y_{t-1}+B_{2} Y_{t-2}+\cdots+B_{p} Y_{t-p}+\varepsilon_{t}, \quad t=1, \ldots, T,
$$

where $p$ is the length of the lag; $Y_{t}$ is a vector of the endogenous variables with dimension $n \times 1 ; \varepsilon_{t}$ is a vector with dimension $n \times 1$ of the independent normally distributed errors with covariance matrix $\Sigma, \varepsilon_{t} \sim \operatorname{IIN}(0, \Sigma) ; B_{l}(l=1, \ldots, p)$ are parameter matrices with dimension $n \times n$.

The augmented Dickey-Fuller (ADF) test is used to check the series for stationarity, and the Johansen test is used to check for the presence of cointegration. In order to determine the number of lags, various information criteria are used, such as the Hannan-Quinn, Schwartz, Akaike, and FPE (Final Prediction Error) information criteria. In view of the results of the above criteria, as well as the fact that the addition of a large number of lags to the VAR model aggravates the problem with the number of estimated parameters, we choose a single lag for our calculations.

Next, we put the VAR into the structural form (2):

$$
A_{0} Y_{t}=c_{0}+A_{1} Y_{t-1}+A_{2} Y_{t-2}+\cdots+A_{p} Y_{t-p}+\epsilon_{t}, \quad t=1, \ldots, T,
$$

where $c_{0}$ is vector of constants with dimension $n \times 1, A_{0}^{-1} A_{j}=B_{j}, \varepsilon_{t}=A_{0}^{-1} \epsilon_{t}$.

Thus, we estimate the impulse responses of investment to a monetary policy shock using SVAR models (with a constant). SVAR identification strategy is described in detail in Section 4.

Using the accumulated impulse response functions, we divide Russian regions into three groups in accordance with their response to monetary policy shock (above, below, and in accordance with the level of reaction of total investments in the country). After that, we estimate three panel vector autoregressions (PVARs) with fixed effects by OLS.

In the second stage of the study, we estimate the selected factors of different monetary policy effects on regional investment using multiple regressions. With a large set of explanatory variables, random noise in the data can lead to significant changes in the estimated values of the coefficients. In such cases, the literature uses 
penalty-based regularisation techniques. For this purpose, L1 or L2 regularisation is added to the standard minimised functional, based on the value of the coefficient vector norm. The LASSO model based on the $\mathrm{L} 1$ regularisation technique allows a choice of the most important variables from the general set of variables and the nullification of the rest, but the remaining coefficients can be unstable. In turn, the Ridge model based on the $\mathrm{L} 2$ regularisation technique delivers more robust estimates for the correlated variables but does not nullify insignificant coefficients. We used the generalising Elastic Net technique, which combines the advantages of both techniques: stable coefficient estimates, as in the Ridge model, and nullification of insignificant coefficients, as in the LASSO model (Hastie et al., 2017, pp. 61-79).

The regression problem using the Elastic Net technique takes the form (3):

$$
\hat{\beta} \in \underset{\beta}{\operatorname{argmin}}\|Y-X \beta\|^{2}+\lambda\left[\alpha\|\beta\|_{1}+(1-\alpha)\|\beta\|_{2}\right] .
$$

In this formulation of the problem, there are two hyperparameters: $\lambda$, which is responsible for the importance of the penalty, and $\alpha$, which weighs LASSO and Ridge. For $\alpha=1$, the model takes the LASSO form, and for $\alpha=0$, the Ridge form. We set hyperparameter $\alpha$ at 0.5 , equidistant from the two extreme cases, as Baybuza (2018), Chakraborty and Joseph (2017) and others have done in similar works. Hyperparameter $\lambda$ is selected using cross-validation on a sample that is not used in the estimation of the model (deferred sampling). In this case, the optimal value of $\lambda$ is determined by optimising the mean squared prediction error using the $\mathrm{k}$-fold cross-validation method $(k=10)$.

As dependent variables, we include in the regression the absolute values of the accumulated impulse responses of investment to monetary policy shock, obtained in the first stage of the study from the estimation of the SVAR models. As independent variables, we include in the regression candidate explanatory factors, the choice of which justified by the transmission mechanism channels (see Section 2).

\section{Data used to estimate VARs}

In order to study the effect of the Bank of Russia monetary policy on investment in 78 regions $^{2}$ of the Russian Federation, we use the quarterly volumes of fixed capital investment for the regions.

We take into account the effect of monetary policy on investment through the channels of the transmission mechanism, the most important of which is the interest rate channel. As the variable characterising monetary policy, we used the RUONIA overnight rate for the interbank market ${ }^{3}$ because it directly affects lending

\footnotetext{
${ }^{2}$ Due to insufficient data, the city of Sevastopol, the Republic of Crimea, the Chechen Republic, and the Chukotka Autonomous Area were excluded from the sample. The regions which include several autonomous areas (Tyumen Region, Arkhangelsk Region) were considered as single wholes.

3 The indicative weighted rate of overnight rouble loans (deposits), which reflects the estimated cost of unsecured overnight rouble borrowing by a standard borrower from among Russian banks with minimal credit risks (Rouble Overnight Index Average, RUONIA). See http://ruonia.ru/
} 
rates for the real sector, acting as an intermediate link between monetary policy and other rates in the economy. The RUONIA quarterly rates were derived as volumeweighted averages from the overnight rates.

In order to account for the exchange rate channel of the transmission mechanism through which monetary policy affects aggregate demand through the exchange rate of the national currency, we used the real effective exchange rate (REER) of the rouble against foreign currencies.

The Bank of Russia analyses the state of the entire economy when it makes decisions on changing the key rate, since, through the transmission mechanism, monetary policy has an effect on consumer and investment spending, and hence on aggregate output and price dynamics (Figure 1). Therefore, we include GDP and CPI (consumer price index) indicators in the model.

In order to account for the effect of monetary policy on investment, we include the M2 money supply as a monetary aggregate. ${ }^{4}$

We choose this set of variables based on assumptions about the channels that may translate a monetary policy shock into investment dynamics, so we do not take into account many other variables. In addition, the VAR model assumes a large number of parameters for estimation, which, in the case of short time series, imposes strict upper restrictions on the number of variables. Therefore, in order to obtain robust estimates, we built VAR models using the indicators listed above.

In order to confirm the robustness of the estimates, two model specifications (with and without money supply), presented in Table 1, were selected. Using these two sets of variables we construct a number of SVAR models (with data sample in a 2010Q1-2019Q2 period).

Table 1. Specifications for VAR model estimations

\begin{tabular}{l|ll} 
& Specification & \\
\cline { 2 - 3 } Factors & VAR 1 & VAR 2 \\
\hline GDP & $*$ & $*$ \\
\hline CPI & $*$ & $*$ \\
\hline RUONIA & $*$ & - \\
\hline Money supply (M2) & $*$ & $*$ \\
\hline REER & $*$ & $*$ \\
\hline Fixed capital investment in the region & $*$ & $*$ \\
\hline
\end{tabular}

Source: compiled by the authors

The necessary data for the real effective rouble exchange rate, the rates of the interbank market, and the money supply are taken from the official website of the Bank of Russia, ${ }^{5}$ and other indicators are taken from the official website of Rosstat. ${ }^{6}$

The investment indicator is converted to real using the price index for investment products. The money supply and GDP are converted to real using the GDP deflator.

\footnotetext{
${ }^{4}$ Money supply was included in the model, since before Bank of Russia's shift to inflation targeting regime this indicator played an important role in economic dynamics.

${ }^{5}$ See https://www.cbr.ru/

${ }^{6}$ See https://rosstat.gov.ru/
} 
We use the recursive identification scheme suggested by Bernanke et al. (2005), whereby the variables are ordered based on the speed of their response to shock, and then the Cholesky decomposition is applied. Various approaches to orthogonalisation of shocks are discussed in a paper by Skrobotov and Turuntseva (2015).

The scheme for the identification of the models is as follows:

- The RUONIA interest rate, exchange rate, and money supply affect the economy with some lag and do not affect GDP or CPI in the current period;

- We assume that in determining its monetary policy, the Bank of Russia takes into account the CPI and may take into account GDP dynamics;

- Regional investment is affected by all variables of the model, and the exchange rate is affected by all but the regional variables.

Seasonal adjustment uses the X-13-ARIMA-SEATS seasonal filter implemented in the 'seasonal' package ${ }^{7}$ of the $\mathrm{R}$ statistical software. A review of the methodological features of seasonal adjustment is presented in a paper by Sapov et al. (2018). All variables, except for the RUONIA interest rate, are considered in logarithms.

When preparing the data, we check them for stationarity and cointegration. According to the results of the augmented Dickey-Fuller test, not all the series are stationary. This means that the original time series should be transformed to stationary ones by first-differencing. The Johansen test also reveals cointegration.

However, our sample covers a period of less than ten years, which does not allow us to identify long-term relationships in the variables. The imposition of inappropriate cointegration relationships can lead to biased estimates and, therefore, bias in the impulse responses derived from the VAR. Hence, the specification of the error correction model is inappropriate in our case.

Additionally, VAR model in first differences may give inconsistent estimates if some of the variables are cointegrated. In this case, the specification in the differences ignores information about the long-term dynamics of the system. At the same time, the data in levels makes it possible to obtain consistent estimates of the coefficients, regardless of the existence of cointegration. The estimated impulse response functions will also be robust estimates of the true impulse responses, especially in the short and medium term (Sims et al., 1990; Bernanke and Mihov, 1997; Carlino and DeFina, 1998; Phillips, 1998).

Based on the above, we choose the VAR model using data in levels as the preferred specification in our paper.

\section{Empirical findings}

\subsection{Decomposition of variation in investment}

Monetary policy has a limited impact on regional investment and other variables. In this subsection, we present the forecast error variance decomposition

${ }^{7}$ See http://www.seasonal.website/ 
(FEVD), which allows us to assess the contribution of monetary and non-monetary factors to the explanation of the dynamics of regional investment. We consider the RUONIA interest rate as a monetary factor.

Figure 2 shows the variance decomposition of the investment variable in Russia for eight quarters (the rationale for choosing eight quarters is given in Section 5.2). In general, the contribution of changes in monetary factors to investment variance is about $8-10 \%$. Also, GDP and CPI shocks make a significant contribution to investment variance.

Figure 2. Decomposition of investment variance in Russia for eight quarters

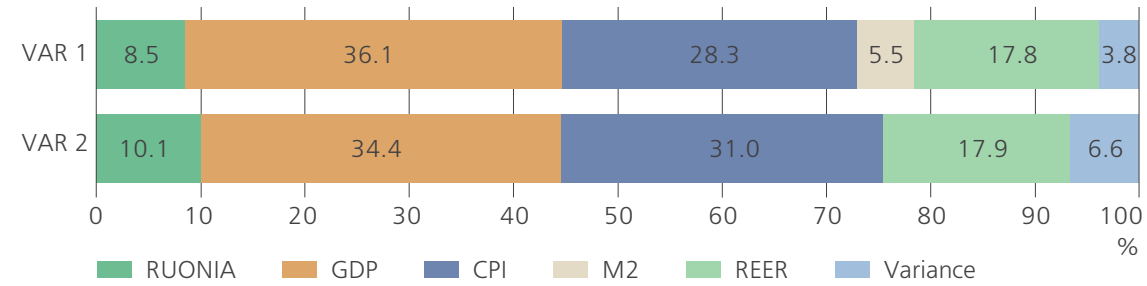

Source: authors' calculations

According to Rosstat, the share of credit funds in investment financing accounts on average for $9 \%$, while the share of own funds in financing is about $50 \%$ (Table 2). This suggests that monetary factors make relatively small contribution to explaining the dynamics of investment.

Table 2. Structure of fixed capital investment in Russia by source of financing, \%

\begin{tabular}{l|l|l|l|l|} 
Year & Equity & Raised funds & Including & \\
\cline { 4 - 5 } & & & Budgetary funds & Bank loans \\
\hline Average for $2010-2019$ & 49.0 & 51.0 & 17.4 & 9.2 \\
\hline
\end{tabular}

Note: In addition to the budget and loans, Rosstat includes the funds of organisations and the population for equity construction, borrowings from other organisations, investments from abroad, extra-budgetary funds, and other funds.

Source: Rosstat

In addition, we analyse the decomposition of investment variance by region. Figure 3 of the Appendix (see online version of the paper) shows the decomposition of the variance of the regional investment variable over eight quarters in VAR 2 (the model specification is presented in Table 1). The analysis shows that changes in the RUONIA interest rate explain up to $32 \%$ of the investment variance across different regions.

At the same time, the contribution of several other factors (GDP, CPI, money supply, and exchange rate) to regional investment variance is greater than the contribution of the interbank market rate and is up to $45 \%$ for GDP, up to $30 \%$ for the CPI, and up to $34 \%$ for the exchange rate for some regions. Figure 4 in the Appendix shows a similar variance decomposition for the VAR 1 model estimates. 


\subsection{Functions of investment impulse responses to interbank market rate shock}

In the first stage of the study, we estimate the effect of monetary policy on investment in Russian regions using SVAR based on data for the period from 2010Q1 to 2019Q2. Analysing the impulse response functions, we can say that the full effect of a tightening monetary policy shock on investment takes up to 8-12 quarters in most regions, and the maximum decrease in investment from a monetary policy shock of one standard deviation reaches in eight quarters $-0.34 \%$.

Our findings are consistent with the Bank of Russia's estimates ${ }^{8}$ for the country, in which, in the first stage of transmission (Figure 1), a change in the key rate is instantly translated into a similar change in the overnight rates in the interbank lending market. A change in money market rates may be translated into a change in long-term rates on loans and deposits of up to 6-9 months. Bank lending in the Russian economy changes after another 1-2 years. Since this paper examines the effect of monetary policy on investment that depends on bank lending, the effect on investment is fully manifested in 8-12 quarters, which is also confirmed by our estimations for individual regions.

Tables 1 and 2 in the Appendix show the characteristics of the accumulated impulse responses of log investment to an increase in RUONIA by one standard deviation for the two models and for 78 regions, indicating for each the significance of the response, the minimum response, the maximum response, and the quarters in which those are achieved. In order to analyse the significance of the impulse responses, we estimate $80 \%$ confidence intervals using the bootstrap method (1,000 iterations). For example, Table 1 of the Appendix shows that most regions (59 out of 78) are characterised by significant investment response to monetary policy shock.

On the heat map of Russia, we show the cumulative investment impulse responses to an increase in RUONIA by one standard deviation for a period of eight quarters using the VAR 2 model estimates (Figure 3). The right-hand scale has a colour palette showing the level of investment response to monetary policy shock by region. Figure 1 of the Appendix show similar heat map for VAR 1 model estimates. The heat map shows that the cumulative responses across regions differ in the extent to which monetary policy affects investment.

The largest decline in investment eight quarters after the increase in the interbank market rate was revealed in such regions as Khabarovsk Region, Amur Region, Altai Region, Leningrad Region, the Jewish Autonomous Region, Kurgan Region, and the Republic of Adygea.

Also, in many regions, there is a less pronounced effect on investment in eight quarters after monetary policy tightening, and the largest increase in investment was found in Magadan Region, as well as in regions of the European part of Russia, such as Novgorod Region, Rostov Region, Volgograd Region, and Tambov Region (Figure 3).

${ }^{8}$ Monetary Policy Guidelines for 2020-2022. See https://www.cbr.ru/eng/about_br/publ/ondkp/ 
Figure 3. Heat map of cumulative investment responses to monetary policy shock according to VAR 2 model estimates for eight quarters

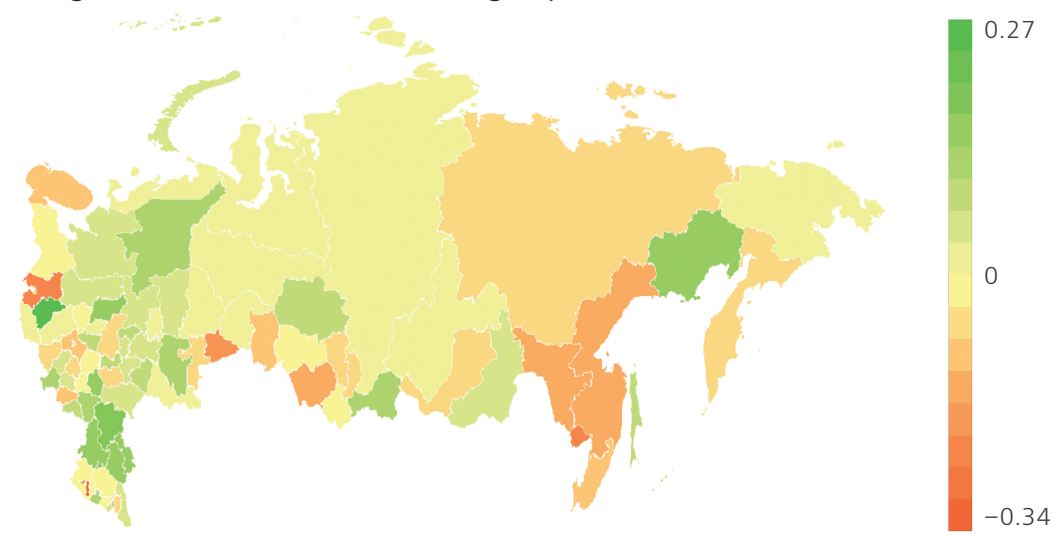

Source: authors' calculations

We divide the Russian regions into three groups by their response to monetary policy shock according to the VAR 1 and VAR 2 model estimates as follows. We compare the cumulative impulse responses of regional investment for eight quarters with a 90\% confidence interval for the response of Russian investment in total (the impulse response function of Russian investment according to the VAR 2 model estimates is depicted in Figure 2 of the Appendix). The subdivision of regions according to their response to monetary policy shock turns out to be robust to the choice of the model. The resulting clusters of regions according to the VAR 2 model estimates are presented in Table 3.

The parameters of the cumulative impulse responses are calculated for the resulting groups of regions. Figure 4 includes the mean responses and mean confidence intervals for the three groups using the VAR 2 model estimates and shows the extent of the regional heterogeneity of the effect of monetary policy on investment.

Figure 4. Parameters of cumulative investment responses to monetary policy shock according to VAR 2 model estimates

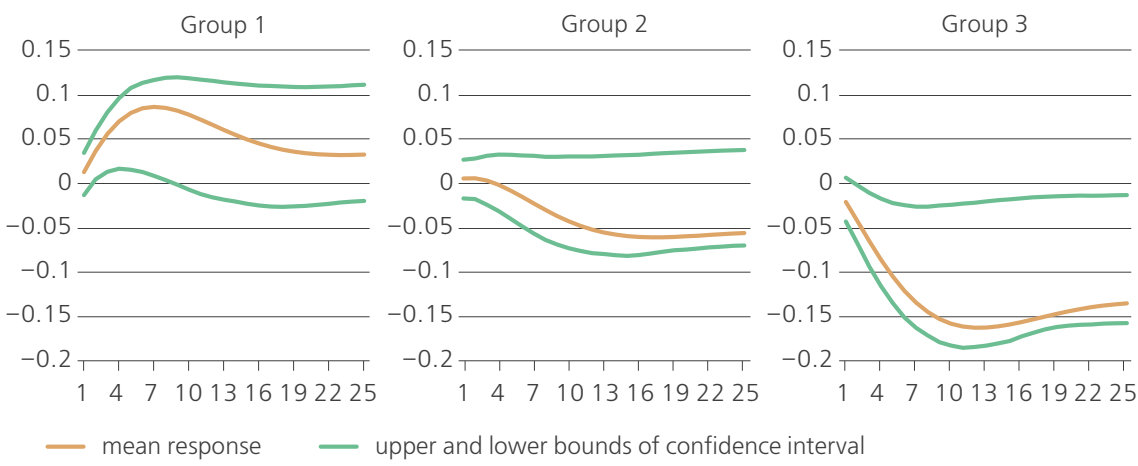

Source: authors' calculations 
Table 3. Clusters of Russian regions according to VAR 2 model estimates

\begin{tabular}{|c|c|c|}
\hline $\begin{array}{l}\text { Group } 1 \\
\text { (investment response above } \\
\text { national confidence interval) }\end{array}$ & $\begin{array}{l}\text { Group } 2 \\
\text { (investment response within } \\
\text { national confidence interval) }\end{array}$ & $\begin{array}{l}\text { Group } 3 \\
\text { (investment response below } \\
\text { national confidence interval) }\end{array}$ \\
\hline Belgorod Region & Ivanovo Region & Kursk Region \\
\hline Bryansk Region & Tver Region & Lipetsk Region \\
\hline Vladimir Region & Ryazan Region & Moscow \\
\hline Voronezh Region & Kaliningrad Region & Moscow Region \\
\hline Kaluga Region & Pskov Region & Smolensk Region \\
\hline Kostroma Region & Republic of Karelia & Tula Region \\
\hline Oryol Region & Krasnodar Territory & Yaroslavl Region \\
\hline Tambov Region & Orenburg Region & Leningrad Region \\
\hline Arkhangelsk Region & Udmurt Republic & Murmansk Region \\
\hline Vologda Region & Sverdlovsk Region & Republic of Adygeya \\
\hline Saint Petersburg & Tyumen Region & Nizhny Novgorod Region \\
\hline Novgorod Region & Krasnoyarsk Territory & Penza Region \\
\hline Komi Republic & Irkutsk Region & Kurgan Region \\
\hline Astrakhan Region & Novosibirsk Region & Chelyabinsk Region \\
\hline Volgograd Region & Altai Republic & Altai Territory \\
\hline Rostov Region & Stavropol Territory & Kemerovo Region \\
\hline Republic of Kalmykia & & Omsk Region \\
\hline Kirov Region & & Republic of Khakassia \\
\hline Samara Region & & Primorye Territory \\
\hline Perm Territory & & Khabarovsk Territory \\
\hline Saratov Region & & Amur Region \\
\hline Ulyanovsk Region & & Kamchatka Territory \\
\hline Republic of Bashkortostan & & Republic of Buryatia \\
\hline Mari El Republic & & Republic of Sakha (Yakutia) \\
\hline Republic of Mordovia & & Jewish Autonomous Region \\
\hline Republic of Tatarstan & & Kabardino-Balkar Republic \\
\hline \multicolumn{3}{|l|}{ Chuvash Republic } \\
\hline \multicolumn{3}{|l|}{ Tomsk Region } \\
\hline \multicolumn{3}{|l|}{ Republic of Tyva } \\
\hline \multicolumn{3}{|l|}{ Magadan Region } \\
\hline \multicolumn{3}{|l|}{ Sakhalin Region } \\
\hline \multicolumn{3}{|l|}{ Zabaikalye Territory } \\
\hline \multicolumn{3}{|l|}{ Republic of Ingushetia } \\
\hline \multicolumn{3}{|l|}{ Republic of Daghestan } \\
\hline \multicolumn{3}{|l|}{ Republic of North Ossetia - Alania } \\
\hline Karachay-Cherkess Republic & & \\
\hline
\end{tabular}

Source: authors' calculations

Also, in order to confirm the robustness of the results, Figure 5 of the Appendix shows a graph of the mean responses and mean $80 \%$ confidence intervals (1,000 bootstrap iterations) with a changed order of variables in the Cholesky decomposition (the RUONIA and REER variables in the VAR models were swapped). The impulse responses remain virtually unchanged. 


\subsection{Panel vector autoregression}

For the clusters of regions presented in Section 5.2 PVARs with fixed effects are estimated and the investment impulse response functions for a tightening monetary policy shock are obtained (Figure 5 ). The $80 \%$ confidence intervals are estimated using the bootstrap method (1,000 iterations).

Figure 5. Cumulative investment responses to a tightening monetary policy shock according to PVAR model estimates
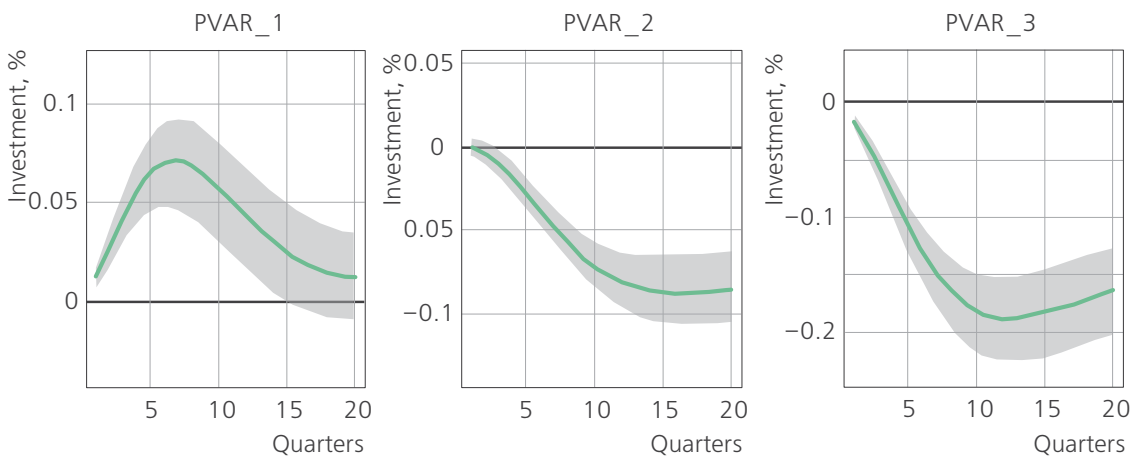

Source: authors' calculations

In Group 1, the effect of a tightening monetary policy shock on investment appears to be positive, and the resulting investment growth is $0.07 \%$.

In Group 2, the effect of a tighter monetary policy on investment is slight: after 15 quarters, a decrease in investment of up to $-0.09 \%$ is observed.

In Group 3, the maximum adverse effect of a tightening monetary policy shock on investment is achieved after 10-12 quarters, and the resulting decline in investment is $-0.2 \%$, twice as strong as in Group 2.

The panel regression results are consistent with the impulse response functions obtained earlier and confirm the differing monetary policy effects on regional investment.

\subsection{Reasons for different monetary policy effects}

In the first stage (Section 5.2), we obtained the cumulative impulse response functions, which reflect the different quantitative effects of monetary policy shock on regional investment. In the second stage, we aim to identify the reasons for this heterogeneity in the context of factors based on the channels of the transmission mechanism (Section 2).

As dependent variables, we took the absolute cumulative investment responses for a certain quarter after a monetary policy shock, which we obtained in the first stage of the study from the estimation of the SVAR models. This technic of 
estimating the response sensitivity to factors regardless of the direction of effect is often used in the literature. The independent variables are the average values over the period the following annual indicators: the sectoral structure of GRP (the interest rate channel of the transmission mechanism), the share of loans to SMEs in the total volume of loans to legal entities (the broad credit channel), and the ratio of imports to GRP (the exchange rate channel). Thus, we associate the impulse response of investment with variables that characterise the intensity of the effect of the interest rate, credit, and exchange rate channels of the transmission mechanism on the regional economy.

In addition to the indicators listed above, we consider the other variables that may contribute to an explanation of regional differences: workforce productivity 9 and the investment attractiveness index.

The investment attractiveness index is calculated based on 2018 ratings by the National Rating Agency; ${ }^{10}$ the higher the rating, the more attractive the region is for investment. The share of loans to SMEs was calculated using the Bank of Russia data for 2010-2018, and the structure of GRP, workforce productivity, and the ratio of imports to GRP were calculated using the Rosstat data for 2010-2017.11

In addition, to identify the reasons for the regional differences in our paper, we used the indicator of business risks ${ }^{12}$ for 2010-2018 from the Bank of Russia's Enterprises Monitoring. ${ }^{13}$ This indicator is an aggregation of self-assessed change in business risks for an enterprise. In our opinion, underlying factors for the indicator affect the investment activity of enterprises; with lower risk intensity, the investment opportunities for enterprises become broader.

In addition to the explanatory factors listed, the regression included dummy variables responsible for the region's affiliation with a federal district (FD) to take into account the factors specific to the region.

We used the Elastic Net regularisation technique, the choice of which is justified in Section 3. The results are shown in Table 4.

The adjusted $R^{2}$ is $0.15-0.31$. Table 5 of the Appendix shows the calculation of the standard error by the bootstrap method (1,000 iterations).

The significant factors explaining the regional differences in the response of investment to monetary policy shock, which the Elastic Net method picks in the model, are the shares of agriculture, mining and quarrying, manufacturing, construction, imports to GRP ratio, and the indicator of business risks.

\footnotetext{
${ }^{9}$ Workforce productivity was calculated as the ratio of GRP to the average annual number of workers in the region.

${ }^{10}$ See https://www.ra-national.ru/ (in Russian).

${ }^{11}$ Since, at the time of the research, data on GRP were available only until 2017, average values for 2010-2017 were used for GRP and for the structure of GRP.

12 The indicator is the difference between the share of enterprises that note an increase in business risks and enterprises that note a decrease, i.e., the balance of the answers of the enterprises in the region to the question: 'How, in your opinion, have business risks changed recently?'

${ }^{13}$ See https://www.cbr.ru/mp/ (in Russian).
} 
It looks like regions with higher shares of manufacturing, agriculture, and construction are more responsive to monetary policy. The higher the risks for the enterprises of the region, the greater the effect of monetary policy shock on investment. Similar findings were obtained by the authors of this paper in a previous study of the regions of Siberia (Shevelev et al., 2020).

Table 4. Regression results using Elastic Net

\begin{tabular}{lllllllll}
\hline Model & VAR 1 & & & \multicolumn{7}{l}{ VAR 2 } & \\
\hline Number of quarters after shock & 2 & 4 & 6 & 8 & 2 & 4 & 6 & 8 \\
\hline SME loans & 0 & 0 & 0 & 0 & 0.047 & 0.012 & 0 & 0 \\
\hline Agriculture & 0.145 & 0.087 & 0.026 & 0 & 0.202 & 0.218 & 0.114 & 0.050 \\
\hline Mining and quarrying & -0.103 & -0.180 & -0.231 & -0.244 & -0.011 & -0.063 & -0.117 & -0.125 \\
\hline Manufacturing & 0 & 0.064 & 0.007 & 0.038 & 0 & 0.168 & 0.002 & 0.006 \\
\hline Electric power & 0 & 0.033 & 0.010 & 0.019 & 0 & 0.028 & 0 & 0.007 \\
\hline Construction & 0.064 & 0.130 & 0.070 & 0.024 & 0 & 0.090 & 0.025 & 0 \\
\hline Trade & 0 & 0 & 0 & 0 & 0 & 0 & 0 & 0 \\
\hline Public administration & 0 & 0.012 & 0.021 & 0 & 0 & 0 & 0 & 0 \\
\hline Education & 0.065 & 0.125 & 0 & 0 & 0 & 0.157 & 0 & 0 \\
\hline Investment attractiveness index & 0 & 0 & 0 & 0 & 0 & 0 & 0 & 0 \\
\hline Labour productivity & -0.067 & 0 & 0 & 0 & 0 & 0 & 0 & 0 \\
\hline Imports to GRP ratio & -0.017 & -0.100 & -0.110 & -0.145 & 0 & -0.117 & -0.075 & -0.089 \\
\hline Business risks & 0.263 & 0.213 & 0.119 & 0.077 & 0.214 & 0.265 & 0.127 & 0.066 \\
\hline North-Western FD & 0.053 & 0.171 & 0.196 & 0.227 & 0 & 0.133 & 0.067 & 0.056 \\
\hline Southern FD & 0.120 & 0.249 & 0.228 & 0.220 & 0.043 & 0.248 & 0.246 & 0.253 \\
\hline Volga FD & -0.002 & -0.010 & -0.036 & -0.081 & 0 & -0.040 & -0.047 & -0.103 \\
\hline Ural FD & 0 & 0 & 0 & 0.033 & -0.011 & -0.021 & 0 & 0 \\
\hline Siberian FD & -0.144 & -0.079 & 0 & 0 & -0.063 & -0.081 & 0 & 0 \\
\hline Far Eastern FD & 0.193 & 0.334 & 0.295 & 0.283 & 0 & 0.295 & 0.210 & 0.166 \\
\hline North Caucasus FD & 0.003 & 0 & 0 & 0 & 0 & -0.010 & 0 & -0.033 \\
\hline Observations & 78 & 78 & 78 & 78 & 78 & 78 & 78 & 78 \\
\hline $\boldsymbol{R} \mathbf{2}$ & $\mathbf{0 . 3 4}$ & $\mathbf{0 . 4 4}$ & $\mathbf{0 . 3 9}$ & $\mathbf{0 . 3 7}$ & $\mathbf{0 . 2 5}$ & $\mathbf{0 . 4 3}$ & $\mathbf{0 . 3 1}$ & $\mathbf{0 . 2 8}$ \\
\hline Adjusted $\boldsymbol{R}$ & $\mathbf{0 . 2 1}$ & $\mathbf{0 . 3 1}$ & $\mathbf{0 . 2 7}$ & $\mathbf{0 . 2 6}$ & $\mathbf{0 . 1 7}$ & $\mathbf{0 . 2 8}$ & $\mathbf{0 . 2 0}$ & $\mathbf{0 . 1 5}$ \\
\hline Source: authors'calcus & & & & & & & & 0 \\
\hline
\end{tabular}

Source: authors' calculations

The results presented in Table 4 also show the following: the larger the share of mining and quarrying in GRP, the smaller the investment response to a monetary policy shock. This may be associated with the foreign financing of this economic sector and the orientation of extractive industries to the world market.

In order to confirm the robustness of the results, we also calculated regression models in which the responses from VAR models with a changed variable order act as dependent variables (the RUONIA and REER variables were swapped in the Cholesky decomposition; the results of these regression calculations are shown in Table 3 of the Appendix). In addition, Table 4 of the Appendix presents the results of regression without regularisation, where the standard error and the level of significance are indicated for each variable. The results remain virtually unchanged. 


\section{Conclusion}

In this paper, we estimate the effects of monetary policy shocks on fixed capital investment using SVARs for the regions of Russia and identify the factors behind the heterogeneity of such effects.

In the first stage of the study, we obtain the impulse responses of investment in Russian regions to monetary policy shock. The maximum decline in investment eight quarters after a tightening monetary policy shock is $-0.34 \%$, but in some regions there is an increase in investment of up to $0.27 \%$. We also analyse the decomposition of the variance of investment and show that changes in monetary factors can explain up to $34 \%$ of the dispersion of investment across regions.

Using the cumulative impulse response functions, we divide the regions of Russia into three groups according to their response to monetary policy shocks. The subdivision of regions turns out to be robust to the choice of the model. For the groups obtained, we estimate three PVARs and the corresponding investment IRFs for a monetary policy shock. In Group 1, the effect of a tightening monetary policy shock on investment appears to be positive, and the resulting investment growth is $0.07 \%$ on average. In Group 2, the effect of monetary policy on investment is slight: after 15 quarters, a decrease in investment of up to $-0.09 \%$ is observed. In Group 3, the maximum adverse effect of a tightening monetary policy shock on investment is achieved after 10-12 quarters, and the resulting decline in investment is $-0.2 \%$. The panel regression results are consistent with the impulse response functions obtained earlier for individual regions and confirm the differing monetary policy effects on regional investment.

In the second stage, we estimate the significance of various factors in explaining the heterogeneity of the effect of monetary policy on investment using OLS regressions. As a dependent variable, we use the cumulative impulse response functions of investment to changes in the interbank market rate. The regressions are estimated using the Elastic Net regularisation technique. The imports to GRP ratio, business risks, and the share of manufacturing, mining and quarrying, construction, and agriculture in GRP are significant factors that explain the region differences in the response of investment to monetary policy shock. We find that regions with larger shares of manufacturing, agriculture, and construction are more responsive to monetary policy, and the regions with a high share of mining and quarrying are less responsive. This may be associated with the foreign financing of this economic sector and its orientation of extractive industries to the world market, but these conclusions require verification in further research. Also, it is possible to consider alternative schemes for identifying the shock of monetary policy and take into account the spatial relationships between regions.

Appendix is available at 


\section{References}

Aganbegyan, A. G. (2011). Eshche raz o novoy roli bankov v sovremennykh usloviyakh [Once More on the New Role of Banks in Current Conditions]. Den'gi i kredit, 12, pp. 3-8. [In Russian].

Aganbegyan, A. G. (2012). Investitsii - osnova uskorennogo sotsialno-ekonomicheskogo razvitiya Rossii [Investments - the Basis of the Acceleration of the Socio-Economic Development of Russia]. Den'gi i kredit, 5, pp. 11-12. [In Russian].

Anagnostou, A. and Papadamou, S. (2015). Regional Asymmetries in Monetary Policy Transmission: The Case of the Greek Regions. Environment and Planning C: Government and Policy, 34(5), pp. 795-815. https://doi.org/10.1177/0263774X15614679

Arnold, I. and Vrugt, E. (2002). Regional Effects of Monetary Policy in the Netherlands. International Journal of Business and Economics, 1(2), pp. 123-134.

Baybuza, I. (2018). Inflation Forecasting Using Machine Learning Methods. Russian Journal of Money and Finance, 77(4), pp. 42-59. https://doi.org/10.31477/rjmf.201804.42

Bernanke, B. and Mihov, I. (1997). What Does the Bundesbank Target? European Economic Review, 41(6), pp. 1025-1053. https://doi.org/10.1016/S0014-2921(96)00056-6

Bernanke, B. S. and Blinder, A. S. (1992). The Federal Funds Rate and the Channels of Monetary Transmission. American Economic Review, 82(4), pp. 901-921.

Bernanke, B., Boivin, J. and Eliasz, P. (2005). Measuring the Effects of Monetary Policy: A Factor Augmented Vector Autoregressive (FAVAR) Approach. Quarterly Journal of Economics, 120(1), pp. 387-422. https://doi.org/10.1162/0033553053327452

Boschen, J. F. and Mills, L. O. (1995). The Relation Between Narrative and Money Market Indicators of Monetary Policy. Economic Inquiry, 33(1), pp. 24-44. https://doi.org/10.1111/j.1465-7295.1995.tb01844.x

Bulatov, A. (2011). Russia in International Capital Movement: Comparative Analysis. Voprosy Ekonomiki, 8, pp. 66-76. [In Russian]. https://doi.org/10.32609/0042-8736-2011-8-66-76

Carlino, G. and DeFina, R. (1998). The Differential Regional Effects of Monetary Policy. Review of Economics and Statistics, 80(4), pp. 572-587. https://doi.org/10.1162/003465398557843

Chakraborty, C. and Joseph, A. (2017). Machine Learning at Central Banks. Bank of England Working Paper, N 674.

Fraser, P., Macdonald, G. A. and Mullineux, A. W. (2014). Regional Monetary Policy: An Australian Perspective. Regional Studies, 48(8), pp. 1419-1433. https://doi.org/10.1080/00343404.2012.714897

Hastie, T., Tibshirani, R. and Friedman, J. (2017). The Elements of Statistical Learning: Data Mining, Inference, and Prediction. New York: Springer.

Hayo, B. and Uhlenbrock, B. (2000). Industry Effects of Monetary Policy in Germany. In: J. von Hagen and C. J. Waller, eds. Regional Aspects of Monetary Policy in Europe, pp. 127-158. 
Mogilat, A. N. (2017). Obzor osnovnyh kanalov transmissionnogo mehanizma denezhnokreditnoj politiki i instrumentov ih analiza v Banke Rossii [Overview of Monetary Policy Transmission Mechanism Channels and Instruments of their Analysis in the Bank of Russia]. Den'gi i kredit, 9, pp. 3-9. [In Russian].

Phillips, P. C. B. (1998). Impulse Response and Forecast Error Variance Asymptotics in Nonstationary VARs. Journal of Econometrics, 83(1-2), pp. 21-56. https://doi.org/10.1016/S0304-4076(97)00064-X

Ramaswamy, R. and Sloek, T. (1997). The Real Effect of Monetary Policy in the European Union: What Are the Differences? International Monetary Fund Working Paper, N 160.

Ridhwan, M. M., de Groot, H. L. F., Rietveld, P. and Nijkamp, P. (2014). The Regional Impact of Monetary Policy in Indonesia. Growth and Change, 45(2), pp. 240-262. https://doi.org/10.1111/grow.12045

Sapova, A., Porshakov, A., Andreev, A. and Shatilo, E. (2018). Review of Methodological Specifics of Consumer Price Index Seasonal Adjustment in the Bank of Russia. Bank of Russia Working Paper Series, N 33.

Schmidt-Hebbel, K., Serven, L. and Solimano, A. (1994). Saving, Investment, and Growth in Developing Countries. World Bank Policy Research Working Paper, N 1382.

Shcherbakov, V. S. (2015). Razvitie bankovskogo sektora i vozmozhnosti investirovaniya v Sibirskom federalnom okruge [The Development of Banking Sector and Capabilities of Investing in Siberian Federal District]. EKO [ECO], 9, pp. 178-189. [In Russian]. http://dx.doi.org/10.30680/ECO0131-7652-2015-9-178-189

Shevelev, A. A., Kvaktun, M. I. and Virovets, K. S. (2020). Vliyanie denezhno-kreditnoy politiki na investitsii v makroregione Sibir [Influence of Monetary Policy on Investments in the Macroregion of Siberia]. Region: Ekonomika i Sotsiologiya [Region: Economics and Sociology], 2, pp. 168-197. [In Russian]. https://doi.org/10.15372/REG20200208

Sims, C. A. (1980). Macroeconomic and Reality. Econometrica, 48(1), pp. 1-48. https://doi.org/10.2307/1912017

Sims, C. A. (1992). Interpreting the Macroeconomic Time Series Facts: The Effects of Monetary Policy. European Economic Review, 36(5), pp. 975-1000. https://doi.org/10.1016/0014-2921(92)90041-T

Sims, C. A., Stock, J. H. and Watson, M. W. (1990). Inference in Linear Time Series Models with Some Unit Roots. Econometrica, 58(1), pp. 113-144. https://doi.org/10.2307/2938337

Skrobotov, A. and Turuntseva, M. (2015). Theoretical Aspects of Modeling of the SVAR. Moscow: RANERA. [In Russian].

Svensson, E. (2012). Regional Effects of Monetary Policy in Sweden. Lund University Working Paper, N 9.

Young, A. (1993). Lessons from the East Asian NICs: A Contrarian View. NBER Working Paper, N 4482. https://doi.org/10.3386/w4482 